DOCUMENTO DE REFLEXIÓN
NO DERIVADO DE INVESTIGACIÓN

NO DERIVADO DE INVESTIGACION:

\title{
MEMORIA Y AUTOGESTIÓN COMUNTARIA COMO ESTRATEGIA EMANCIPADORA CONTRA EL CONFLICTO Y LA HISTORIA OFICIAL. COMUNIDAD DE PAZ DE SANJOSÉDE APARTADÓ, COLOMBIA.
}

\author{
ESTEBAN CORONEL SALAZAR \\ Facultad Latinoamericana de Ciencias Sociales Flacso. Argentina.
}

Recibido: $21 / 10 / 2015$

Revisado: $21 / 11 / 2015$

Aprobado: 21/12/2015

\section{RESUMEN}

La historia es muestra de los sucesos más importantes, pero reservadamente puede integrarse a proyectos que avanzan hacia sus propios objetivos. Cuando imperan las condiciones que impone una historia de conflicto solo se dan dos opciones: o subordinarse al discurso dominante, o ir por una historia libre. En Colombia y Latinoamérica, la historia se ha subordinado a diversos discursos hegemónicos que a través de violentos lenguajes, han impuesto los imaginarios más convenientes para intereses excluyentes que niegan la memoria y la voz de los oprimidos. La Comunidad de Paz de San José de Apartadó en el Urabá Antioqueño-Colombia, refleja la experiencia de una comunidad, que en la urgencia de crear otra historia que enfrente a la hostil historia "oficial"y reivindique su memoria, construyó todo un proyecto de autogestión comunitaria que niega la lógica de un conflicto histórico que tiene como invariables la violencia y la impunidad.

Palabras clave: Memoria, autogestión comunitaria.

\section{ABSTRACT}

History is a sample of the most important events, but it can be quietly integrated into projects that advance towards their own objectives. When the conditions imposed by a history of conflict prevail, only two options are given: either subordinate to the dominant discourse or go through a free history. In Colombia and Latin America, history has been subordinated to various hegemonic discourses that, through violent languages, have imposed the most convenient imaginaries for excluding interests that deny the memory and voice of the oppressed. The Peace Community of San José de Apartadó in the Urabá Antioqueño-Colombia, reflects the experience of a community, which in the urgency of creating another story that confronts the hostile "official" story and reclaims its memory, built a whole project of community self-management that denies the logic of a historical conflict that has invariable violence and impunity.

Key words: Memory, community self-management. 


\section{Para aclarar el inicio}

Los cientistas sociales sufrimos de cierta mezquindad tendiente al "Yo puedo explicarlo todo", sin embargo hay ciertos temas (como la memoria por ejemplo) que por más bien estructurada que parezca su teoría, esencialmente siempre habrá una desvinculación del proceso apreciativo de lo que significan ciertas cosas para ciertas personas o grupos. Es por esta razón que es importante que cualquier tipo de proceso de construcción de la memoria y de la historia misma, sea fundado a través de un proceso de autogestión, pues es a través de estos procesos que la historia se vuelve real, si se considera que la voz de los oprimidos y los silenciados conocen los detalles de la historia los cuales no se conocen por la conveniente mano de la dominación y su forma de construcción de memoria, lo que adquiere mayor relevancia en contextos de conflicto.

El concepto de Comunidad de Paz posee un sentido diverso que requiere amplios marcos interpretativos no solo de la esencia de su surgimiento, sino también de los procesos internos emprendidos para defender su proyecto socio-comunitario en el cual, los conceptos de Memoria, Autogestión y Resistencia se articulan de formas muy especiales.

La Autogestión puede definirse como la sociedad en construcción ${ }^{1}$. La multi-dimensionalidad que adquiere el concepto de autogestión advierte sobre la diversidad de campos sobre los que han sido aplicadas sus prácticas. Entre ellos está, lo económico, lo político, lo cultural, lo social, lo educativo, soberanía alimentaria, salud, y entre otros, la memoria.

1. Pierre Rosanvallon, La Autogestión (Madrid: Fundamentos, 1979), 25.
El objetivo aquí, será desarrollar la descripción de algunos procesos autogestionarios en la $\mathrm{CPz}$ que han sido motivados no solo para responder al conflicto y a la historia de violencia sobre el territorio y la comunidad, sino también como iniciativas para la protección de su memoria, de su historia y de su proyecto de resistencia civil.

Por todo lo anterior, este trabajo no pretende hacer un abordaje de la teoría y de los autores del campo de la memoria, lo que se pretende es describir a trazos gruesos, una experiencia real, de una comunidad real, que a través del sentido propio que le dieron a la memoria, redireccionaron las premisas interpretativas sobre las que se entiende la convivencia social y les permitieron resistir pacíficamente, la opresión de un sistema irresponsable.

\section{Urabá: memoria de la violencia e historia de la omisión}

El Estado se ha desentendido históricamente del Urabá, muchos documentos de análisis histórico lo evidencian ${ }^{2}$. La memoria nacional, le ha dado la configuración de zona de alta peligrosidad y casi prohibida; un lugar marginal, en la que impera la ley del más fuerte ${ }^{3}$.

La violencia traía el impulso de las disputas partidistas que se pueden rastrear desde los años 30. Se habla de más de 200.000 muertes en toda Colombia, sin embargo, esta violencia raramente

2. Fernán González. "Espacio, conflicto y poder: las dimensiones territoriales de la violencia y la construcción del Estado en Colombia", Sociedad y Economía, no. 17 (2009): 199-201, consultado 13 mayo, 2015, http:// www.globethics.net/gel/4142919

3. Claudia Steiner. Imaginación y poder. El encuentro del interior con la costa en Urabá, 1900-1960 (Medellín: Universidad de Antioquia, 2000), 2. 
suscitaba investigaciones o respuestas eficaces por parte de las autoridades ${ }^{4}$.

El acuerdo del Frente Nacional-F.N en $1958^{5}$, garantizaría la impunidad de los crímenes partidistas y de todas sus víctimas.

$\mathrm{Al}$ alternarse el poder, se estaban asegurando la continuación de su dominio, y además enterrarían cualquier chance de esclarecer hechos sobre las víctimas; es decir: el pacto político aseguró, impunidad.

El F.N, había instituido la negación, supresión y olvido de la diversidad del pensamiento y la divergencia en Colombia, sin embargo, también se habían generado oposiciones por parte de grupos que el acuerdo no consideraba y que crecían desde mediados de los 60. Esto crearía nuevos escenarios de violencia esta vez reflejados por grupos armados producto del exclusionismo del esquema como las Fuerzas Armadas Revolucionarias de Colombia-FARC y el Ejército de Liberación Nacional-ELN, por citar solo dos casos.

Los años 70, harían surgir un fenómeno que atravesaría de ahí en adelante la historia y la memoria del país: el narcotráfico; que desplegaría impresionantes niveles de violencia en los 80 y 90 , asesinando personalidades políticas, judiciales, legislativas, entre otros ${ }^{6}, y$ utilizando el terrorismo como una de

4. Mary Roldán. "Violencia, colonización y la geografía de la diferencia cultural en Colombia", Análisis Político, no. 35 (1998): 3-4.

5. El Frente Nacional fue una coalición política y electoral entre liberales y conservadores, vigente en Colombia de 1958 a 1974. Las principales características de este período fueron la sucesión de cuatro períodos (16 años) de gobierno de coalición; distribución equitativa de ministerios y burocracia en las tres ramas del poder público; candidato presidencial elegido por acuerdo bipartidista; y distribución igualitaria de los escaños parlamentarios.

6. El caso de la Unión Patriótica-UP es un caso tristemente célebre que ilustra perfectamente esa época $\mathrm{y}$ las practicas históricas de la violencia, y que seguramente permanecen vigentes hoy. sus principales estrategias en campo y ciudad.

\section{Contexto histórico-político y surgimiento de la comunidad de paz}

En Colombia, al menos desde los años 50 el conflicto no cesa. Su focalización rural, su escalonamiento durante los 60 y 70 y su intensificación durante los 80 y 90 , llevaron a que muchas poblaciones (especialmente campesinas, indígenas y afrodescendientes), empiecen a buscar las formas de darle un alto a la dinámica que el conflicto estaba imponiendo sobre la vida y la historia de la región y empezaron a reflexionar en la necesidad de crear sus propias formas de construir sociedad.

La necesidad de crear espacios de protección civil era urgente. La diócesis de Apartadó y el CINEP7 ${ }^{7}$, comenzaron a discutir algunos instrumentos humanitarios que garantizaran la protección de los civiles. Así se empieza a pensar en zonas neutrales, en las que se respete la vida de la población civil. Pero esta denominación traería ciertas particularidades ${ }^{8}$. El término "neutralidad" fue desestimado tras el uso que de él hizo la gobernación de Antioquia, según la cual la neutralidad se declaraba por decreto, regía sobre territorios y no sobre comunidades e implicaba acogerse a la protección del Estado a través del Ejército ${ }^{9}$.

Los pobladores objetaron la idea y pensaron una nueva propuesta empezando a hablar de Comunidades de Paz. Estas eran declaradas por población no

7. Centro de Investigación y Educación Popular. Colombia. http://www.cinep2015.org/Old/2014_V1/

8. Gloria Cuartas. Ante la impunidad y la indiferencia. La experiencia de memoria, verdad y vida de la comunidad de Paz de San José de Apartadó (Bogotá: Universidad Autónoma de Colombia, 2007), 34-40.

9. Javier Giraldo. Fusil o toga, toga y fusil (Bogotá: Códice, 2010), 35. 
combatiente residente del corregimiento que libremente se comprometiera con los estatutos y reglamentos determinados por la misma comunidad, y en las que el estatuto de protección recae sobre la comunidad y no sobre el territorio ${ }^{10}$.

La población empieza así a re-conceptualizar inmutabilidades que habían marcado la historia del Urabá como el desarraigo, la violencia y el dominio de intereses económicos. Esta propuesta comunitaria transgrede las lógicas históricas de apropiación y explotación privada, con lógicas comunitarias de trabajo y convivencia, dando muestra que en una región de destierros es posible la pertenencia del territorio a través de la dignidad, el trabajo colectivo y la organización responsable ${ }^{11}$. De esta forma, el 23 de marzo de 1997, los habitantes de San José de Apartadó se declararon oficialmente Comunidad de Paz.

Los residentes del corregimiento y desplazados de 17 veredas, se declararon al margen del conflicto exigiendo a todos los actores armados el respeto por su vida, sus bienes, su territorio y su derecho a la paz. Pero su exigencia seria rápidamente desestimada. Solo cinco días después de la declaración, hubo una incursión paramilitar en la que fueron asesinados varios campesinos; esa semana empezaría un verdadero baño de sangre que buscaría aniquilar desde su nacimiento a la $\mathrm{CPz}^{12}$.

Ante esto, la CPz se fortificó internamente con estrategias solidarias como grupos de trabajo, olla comunal, gestión de cooperación, etc., que le permitieron soslayar algunas necesidades que se iban presentando, pero los grupos armados

10. Esperanza Hernández y Marcela Salazar. Con la esperanza intacta: experiencias comunitarias de resistencia civil no violenta (Bogotá: Oxfam-GB, 1999)

11. Cuartas, Ante la impunidad y la indiferencia, 41.

12. Giraldo, Fusil o toga, 33-43. intensificarían su agresividad y empezaron a utilizar tácticas de bloqueos económicos y exterminio ${ }^{13}$.

Las denuncias de la comunidad y del acompañamiento nacional e internacional poco efecto surtieron en las autoridades nacionales, así que se decidió llevar las denuncias a organismos internacionales, también sin mucho efecto. Esto daría origen a un impresionante trabajo de cartografía histórica de la violencia en la comunidad, que es hoy una evidencia para el mundo, de la construcción de memoria y de su historia de agresiones. ${ }^{14}$

\section{Memoria y autogestión comunitaria}

La memoria atraviesa el proceso de la $\mathrm{CPz}$ e incide en todas sus dimensiones de desarrollo (Política, económica, social y cultural); es la conciencia sobre su memoria lo que les ha permitido construir diferentes iniciativas de Autogestión que respondan efectivamente a las lógicas de sumisión de la vida que se estaban imponiendo en esos territorios.

$\mathrm{La} \mathrm{CPz}$ ha entendido que siempre ha habido fuerzas que quieren que su proyecto desaparezca y no deje ninguna huella. Esta conciencia del peligro de su desaparición, ha hecho que la comunidad identifique los componentes que sostienen su proyecto para así fortalecer su historia vivida.

13. Eduar Lanchero. El caminar de la resistencia: una búsqueda histórica (Bogotá: Códice, 2000), 71-72.

14. Mi intención no es describir las interminables injusticias cometidas contra la Comunidad de Paz, mi objetivo es mostrar un rasgo contextual que no iba a cambiar en ningún momento para ellos y que permanecería marcando su memoria permanentemente. En el sitio web de la comunidad se puede encontrar un extenso informe que hace referencia incluso a agresiones hechas antes de la declaración de la comunidad, hacia pobladores de la zona. Sin duda es un impresionante trabajo de sistematización y acopio de información, pero sobre todo de autogestión de la memoria. 
$\mathrm{Su}$ trabajo en los cultivos recuerda su lucha contra el hambre y los cercos alimenticios; la sistematización de sus agresiones conmemora las vidas entregadas por todos quienes han apoyado e integrado el proyecto comunitario; sus parques y monumentos reproducen sus escenarios de reivindicación y lucha; pinturas, manillas, collares, poemas, canciones, símbolos, himnos, videos, documentales, grabaciones, obras de teatro, etc. Todo hace parece de un gran acervo histórico-cultural que protege su memoria y su proyecto de paz.

Para ilustrar esta visión, se describen aquí cuatro imágenes de la memoria de la $\mathrm{CPz}$ que ciertamente han inspirado procesos de autogestión para el fortalecimiento de sus estrategias de resistencia y para la búsqueda de nuevas formas de convivencia social.

\section{Asesinatos, desapariciones e impunidad}

En estos 18 años más de 300 integrantes fueron asesinados, la mayoría de forma terrible; 348 amenazas de muerte y destrucción, al menos 100 casos de tortura y 200 montajes judiciales; más de 50 desplazamientos colectivos; 324 ocupaciones ilegales por parte de paramilitares en estrecha coordinación con el ejército y acompañando sus incursiones con todo tipo de ultrajes y afrentas a la dignidad; 186 ocupaciones ilegales por parte de la fuerza pública en abierta violación de las leyes y con aterrador desprecio por la dignidad humana; abusos sexuales, golpizas, campañas de difamación, empadronamientos ilegales, profanación de cadáveres; robos de sus animales de carga; pillaje de sus despensas y asalto a los productos que sacan a la venta; destrucción de sus menajes y elementos de sobrevivencia, y numerosas masacres tan terribles como la del 21 de febrero de 2005 con descuartizamiento de niños hasta de 18 meses $^{15}$. Esta es una lista (quizá resumida) de las múltiples formas de agresión que ha sufrido la $\mathrm{CPz}$. La mayoría de estas violaciones a sus derechos no han obtenido justicia; esta es una imagen clara en la memoria de la comunidad.

La rama judicial del país por su parte, se ha distinguido por una obtusa operatividad, una siempre lenta respuesta y una apócrifa eficiencia en los procesos de esclarecimiento y justicia. La historia vivida por la $\mathrm{CPz}$ da cuenta de eso, y es por esa razón que en 2003 declararon ruptura con el sistema judicial, el cual había fracasado en la generación de procesos de justicia y además, obstaculizaba los pocos procesos que se ponían en marcha ${ }^{16}$.

Ante esta dinámica, la $\mathrm{CPz}$, con el apoyo de organizaciones internacionales y nacionales de Derechos Humanos y solidaridad nacional e internacional, ha consolidado un impresionante registro de las agresiones sufridas ${ }^{17}$. Esta sistematización pretende mantener evidencias históricas de sus víctimas, de sus agresiones sin esclarecimientos, de sus integrantes desaparecidos, de la corrupción, de la confabulación para la muerte, etc.

La memoria entonces, es una reconstrucción histórica que denuncia los horrores cometidos contra ellos; es un proceso de verdad, de reconfiguración del tejido social, de juicio a la historia y un recordatorio a la impunidad de que las vidas de sus compañeros nunca es-

15. "Desde los márgenes", Javier Giraldo S. J., consultada 10 mayo, 2015, http://www.javiergiraldo.org/ spip.php?article248

16. Banco de Datos de Violencia Política CINEP, "San José de Apartadó: la otra versión", noche y niebla, Caso Tipo No. 06 (2005): 137-141.

17. El archivo de la sistematización y el registro histórico de agresiones puede ser revisado y descargado de la página web de la $\mathrm{CPz}$ en: http://cdpsanjose.org/ 
tarán en el olvido; “...es un proceso para mantener vivos a quienes ya no lo están"18.

\section{La corrupta relación entre política y violencia}

Una de las particularidades de la personalidad histórica nacional ha sido la aparente facilidad con la que las "fuerzas del bien" se articulan con las "fuerzas del mal" estableciendo feroces pactos secretos.

El Estado aliado con sanguinarios empresarios, el ejército nacional actuando en complicidad con los paramilitares, el narcotráfico operando con la venia de la institucionalidad, señalamientos injustos ${ }^{19}$, negación de servicios sociales, hostigamientos por parte de autoridades, corrupción burocrática, procesos electorales fraudulentos, políticas públicas inoperantes, montajes judiciales, falso sentido de la democracia, función pública clientelar y subordinada a lo privado, etc. ${ }^{20}$.

Para responder a esto, la $\mathrm{CPz}$ en primer lugar ha tomado la decisión general voluntaria de No Votar en procesos electorales; esto demuestra por un lado, que su causa no está contaminada por sectarismos ideológicos; y por otro, evidencia la consciencia de la experiencia de la comunidad sobre la relación histórica y corrupta entre política y vio-

18. CINEP, "San José de Apartadó", 151.

19. En el año 2005, el expresidente Álvaro Uribe Vélez declaró en medios públicos que la comunidad era un escondite de guerrilleros, lo que los convertía inmediatamente en objetivo militar de los ejércitos paramilitares. Para ampliar visitar: http://www. sos-sanjose.org/index.php?id=95

20. En la obra "Fusil o toga, toga y fusil" del año 2010 escrita por el padre Javier Giraldo S.J., se puede encontrar un detallado registro de las atrocidades sufridas por la comunidad de paz de parte de actores legales e ilegales, con testimonios y extractos de informes y publicaciones oficiales. lencia. La CPz diseñó esquemas representativos y participativos en los que la democracia, significa consenso, y no mayoría; su diseño político se basa en espacios de diálogo abierto, plena participación, igualdad representativa y cohesión social asumida desde la horizontalidad.

Estas iniciativas nacen de las imágenes y lecciones que la memoria guarda para ellos, son formas reivindicativas de conceptos deformados por la corrupción humana, con esto, la comunidad busca resignificar imaginarios teóricoprácticos de la vida, que recuperen el sentido de lo político, la honradez y la devoción hacia el otro, un otro visto desde la justicia y el respeto, aspectos aún lejanos en la práctica evidente de la cotidianidad colombiana.

\section{Los bloqueos económicos y cercos de hambre}

Una de las imágenes más duras en la memoria de la $\mathrm{CPz}$ es sin duda los bloqueos económicos y cercos de hambre que establecieron los paramilitares en diferentes oportunidades; estos consistían en la obstaculización del paso de personas, vehículos, animales y el noacceso de víveres y de todo lo que se dirigiera hacia asentamientos de la comunidad mediante el cierre de la única vía de conexión que había. Ahí asesinaban a los miembros y a personas cercanas a la comunidad; como si eso no bastara, empezaron a asesinar también a los conductores de los "chiveros" ${ }^{21}$ que viajaban con provisiones hacia San José

21. Chiveros son los vehículos que se mueven entre el casco urbano y rural de Apartadó. Transportan personas y suministros hacia los asentamientos periféricos de esa área, y son el único canal de abastecimiento y transporte para cientos de familias de la zona. 
y a los propietarios de expendios, tiendas de víveres y comercios de cualquier tipo, además, los paramilitares arrasaban y quemaban las propiedades y los cultivos para acabar las semillas de la comunidad y así matarlos de hambre ${ }^{22}$.

Esta fragilidad los llevó a reflexionar sobre sus niveles de dependencia con el sistema que los oprimía históricamente y con el que ahora se quería romper. La $\mathrm{CPz}$ entonces, emprendió una serie de diagnósticos alimentarios en sus asentamientos. Lo que se hacía básicamente era una encuesta por familia en la que se describía cual era la base alimenticia de cada hogar. Estas encuestas se revisaban y se identificaban patrones de alimentación, es decir, cuáles eran los productos que más se consumían en la comunidad ${ }^{23}$. Todos los productos identificados en el diagnóstico eran aptos para cultivarse en los suelos donde se asentaba la $\mathrm{CPz}$, de esta forma se empezó a planificar la siembra comunitaria de estos productos que serían para el consumo propio de las familias que integraban la $\mathrm{CPz}^{24}$.

La memoria sembrada por el hambre y la dependencia, había desarrollado en la $\mathrm{CPz}$ una necesidad de autoabastecimiento que terminaría convirtiéndose de a poco, en una sólida estrategia de resistencia económica. Con procesos de comercio justo, agricultura orgánica, principios de conservación natural y equilibro ambiental, complementaban un impresionante proceso de autogestión comunitaria en soberanía alimentaria.

22. Cinep, "San José de Apartadó", 16-17.

23. Comunidad de Paz, Sembrando Diariamente la Vida. La construcción Agroalimentaria de la Comunidad de Paz de San José de Apartadó (Bogotá: Arfo, 2010), 36-39.

24. Este diagnóstico arrojó 4 productos principalmente: el arroz, el frijol, el maíz, y la caña.

\section{La Mercantilización del Conocimiento y la Educación Bancaria $^{25}$}

La educación es uno de los principales temas en la comunidad. Ellos son conscientes de que la educación tradicional, ha transformado el saber en mercancía y eso ha trastornado la esencia del conocimiento, pues el conocimiento que se transmite no refleja las luchas sociales ni la reivindicación de la verdad histórica de la lucha contra la opresión; el conocimiento adoctrinado de la educación "oficial" puede cosificarse para ser instrumento de sumisión ${ }^{26}$.

La CPz ha decidido implementar esquemas de educación popular, basados en asientos teóricos como los de Célestin Freinet y Paulo Freire. $\mathrm{La} \mathrm{CPz} \mathrm{se} \mathrm{ha}$ formado en estos criterios y las tareas de la educación son asumidas por ellos mismos ${ }^{27}$. La comunidad es maestra y estudiante. No se expiden títulos o calificaciones, esas son características marginalizantes de la educación bancaria que impulsan la rivalidad y el enfrentamiento ${ }^{28}$.

Existen cuatro áreas específicas de formación en donde se articulan todos los contenidos: Naturaleza (aprenden biología en sus tierras, huertos y corra-

25. Educación Bancaria es una expresión utilizada por el pedagogo brasilero Paulo Freire que se refiere a la deformidad de la educación la cual minimiza o desaparece el poder creador del maestro y del estudiante, amputando su conciencia crítica, y convirtiendo el acto de educar en un proceso depositario de información que subordina el conocimiento a los intereses del agente opresor.

26. Francisco Gutierrez. La educación como praxis política (México: Siglo XXI, 1984), 92-97.

27. Personalidades de la educación popular han estado en la comunidad como es el caso de Lola Cendales, una célebre investigadora y pedagoga latinoamericana, la cual capacitó a los maestros de la comunidad..

28. Paulo Freire, La pedagogía del oprimido 1970 (México: Siglo XXI, Ed. 2005). 
les); Técnica (aprenden matemáticas con sus juegos y con el trabajo comunitario); Memoria y Comunidad (aprenden historia a través de la remembranza del camino recorrido por la comunidad y su contexto histórico); y, Lecto-Escritura (aprenden a leer y a escribir reproduciendo sus historias y describiendo sus tierras); su educación es un proceso de reflexión y concientización sobre la realidad; es un intercambio continuo entre su ambiente circundante, sus miembros, su historia y su objetivo, reescribiendo completamente los conceptos de la intelectualidad.

\section{Conclusiones no conclusiones}

El Estado colombiano se ha caracterizado tradicionalmente por presentar "una tendencia hacia la irresponsabilidad"29. El contexto histórico y la historia vivida, ha llevado a que la $\mathrm{CPz}$ busque establecer una forma de enjuiciamiento a la historia nacional y regional, que ha resultado también, en invaluables lecciones y enseñanzas de tipo universal.

Para la Comunidad de Paz, la memoria se asume como práctica de autogestión ética de la justicia y adquiere varios sentidos: como forma de conmemoración a sus muertos y víctimas; como demanda por justicia y contra la "justicia"; como estrategia de fortalecimiento interno y del tejido social; como forma de resistencia civil noviolenta; como elemento disruptivo de la historia; $y$, seguramente, en muchos sentidos más.

29. Giraldo. "La impunidad", 5.

\section{Mapa geográfico de ubicación de la comunidad de paz en Colombia}

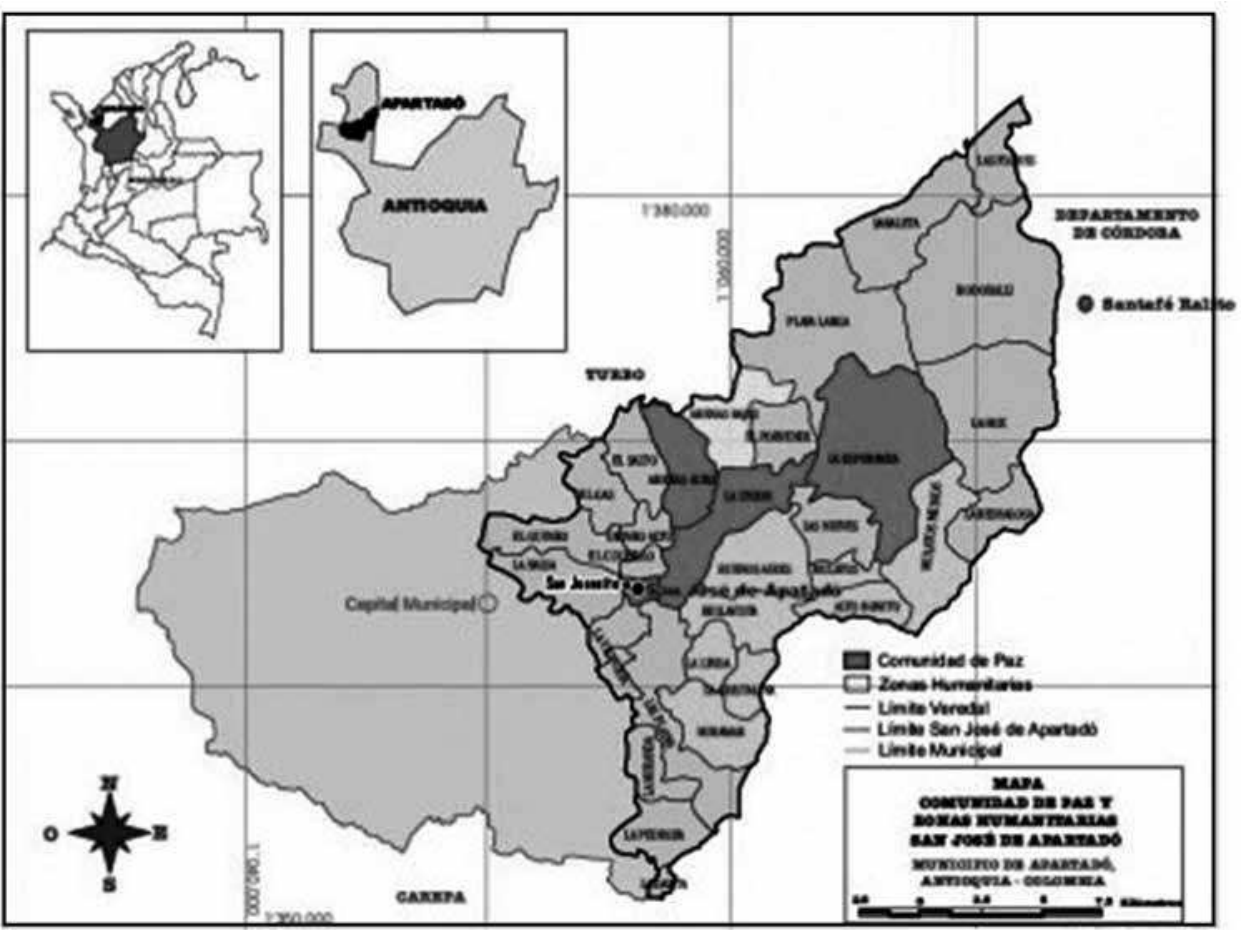

Fuente: Website Comunidad de Paz. 
Los procesos autogestionarios emprendidos por la $\mathrm{CPz}$, son respuestas estimuladas por su sentido de la memoria. La autogestión, la interdisciplinariedad, la diversidad de lenguajes estratégicos, su inmenso valor civil y su inconmensurable amor por la tierra y su herencia campesina, se han articulado armónicamente para crear un impresionante proyecto socio-comunitario, autónomo, honesto, solidario, libre y con un profundo sentido de la conciencia histórica. La memoria del sufrimiento y de la liberación, hacen parte del patrimonio de los pueblos oprimidos; es una estrategia para enfrentar la amnesia de la sociedad, la omisión del Estado y la profunda erosión del significado de derecho.

A través del proceso y la historia de la $\mathrm{CPz}$, se reconocen experiencias de vida alternativa al margen y en medio del conflicto armado, se reconoce un proceso re-significador del sentido de la memoria y de la forma de construcción de las verdades históricas, robusteciendo y amplificando la conciencia colectiva, para hacer de la exaltación y el olvido selectivo del pasado, una herramienta de identidad crítica que estimule un potencial redentor y elimine los elementos condicionantes sobre el futuro.

Cabe agregar que la coyuntura de los diálogos de paz en Colombia, quie- re darle una imagen esperanzadora al futuro, sin embargo, la recurrencia de factores estructurales que no han cambiado en dos siglos y que son los que desataron originalmente el conflicto y la violencia con todas sus consecuencias e impactos conexos, difícilmente cambiarán por un par de firmas en un papel. Es decir, una paz en papel no garantiza nada;

"esa paz es una paz de pocos y realmente nada cambiará para nosotros... La paz se firmará en La Habana y la lucha diaria no cesará... El día que la comunidad deje de luchar, será porque ese día la Comunidad de Paz se ha acabado"30.

Para terminar, es importante remarcar que un abordaje integral de estos temas, requiere entrar en minuciosidades explicadas por la multi-dimensionalidad que comprende la complejidad del asunto, sin embargo, estas líneas pretenden al menos, dar cuenta de vistazos históricos y experienciales que permitan abordar responsablemente, pero a trazos gruesos, esta trascendental experiencia de reconstrucción social y reivindicación humana. Ojalá también pueda ser una forma de reconocimiento a esas vidas y a esa entrega e integridad con la que la Comunidad de Paz creó una experiencia totalmente disruptiva, frente a la lógica impuesta por el contexto y las representaciones dominantes de un sistema irresponsable.

30. Esta y otras impresiones están basadas en múltiples opiniones de integrantes de la Comunidad de Paz, las cuales fueron tomadas durante una visita a la Comunidad realizada entre marzo y abril de 2015. 


\section{BIBLIOGRAFÍA}

Archivo Chile. "El Concepto de Historia en Walter Benjamin". Consultada 11 Mayo, 2015. http://www.archivochile.com/Ideas_Autores/benjaminw/esc_frank_benjam0021.pdf

Centro de Investigación y Educación Popular Cinep, Banco de Datos de Violencia Política. "San José de Apartadó: La Otra Versión". Noche y Niebla, Caso Tipo No. 06 (2005).

Comunidad de Paz. 2010. Sembrando Diariamente la Vida. La construcción Agroalimentaria de la Comunidad de Paz de San José de Apartadó. Bogotá: Arfo.

Cuartas, Gloria. 2007. Ante la impunidad y la indiferencia. La experiencia de memoria, verdad y vida de la comunidad de Paz de San José de Apartadó. Bogotá: Universidad Autónoma de Colombia.

Freire, Paulo. Ed. 2005. La Pedagogía del Oprimido 1970. México: Siglo XXI.

Giraldo, Javier. 2010. Fusil o Toga/Toga y Fusil. Bogotá: Códice.

“Desde Los Márgenes". Consultada 10 mayo, 2015. http://www.javiergiraldo.org/spip.php?article248

"La Impunidad: Consecuencias Jurídicas y Políticas", Revista Justicia y Paz 2, no. 5 (1997): 4-12.

González, Fernán. “Espacio, Conflicto y Poder: Las dimensiones territoriales de la violencia y la construcción del Estado en Colombia". Sociedad y Economía, no. 17 (2009): 185-214. http://www.globethics.net/gel/4142919

Gutiérrez, Francisco. 1984. La Educación Como Praxis Política. México: Siglo XXI.

Hernández, Esperanza y Salazar, Marcela. 1999. Con La Esperanza Intacta: Experiencias Comunitarias de Resistencia Civil No Violenta. Bogotá: Oxfam-GB.

http://cdpsanjose.org/

http://www.cinep2015.org/Old/2014_V1/

http://www.sos-sanjose.org/index.php?id=95

http://www.javiergiraldo.org

http://www.globethics.net/

http://biblioteca.clacso.edu.ar

Lanchero, Eduar. 2000. El Caminar de la Resistencia: Una Búsqueda Histórica. Bogotá: Códice.

Roldan, Mary. "Violencia, colonización y la geografía de la diferencia cultural en Colombia”. Análisis Político, no. 35 (1998): 3-22. http://www.iepri.org/portales/anpol/35.pdf

Rosanvallon, Pierre. 1979. La Autogestión. Madrid: Fundamentos.

Ruíz, M. (23 de mayo de 2005). La Universidad de la Resistencia. Prensa Rural. Recuperado de http://www. prensarural.org/recorre/universidad20050523.htm

Steiner, Claudia. 2000. Imaginación y poder. El encuentro del interior con la Costa en Urabá, 1900-1960. Medellín: Universidad de Antioquia.

Valencia, Alberto. "Memoria y Violencia a los 50 años de "La Violencia en Colombia" de Monseñor Guzmán et al", Sociedad y Economía, no. 23 (2012): 59-84. http://biblioteca.clacso.edu.ar/Colombia/cidse-univaIle/20130528035855/SyE23ok.pdf

\section{LISTA DE ABREVIATURAS}

CINEP: Centro de Investigaciones y Educación Popular.

CPz: $\quad$ Comunidad/es de Paz.

ELN: $\quad$ Ejército de Liberación Nacional.

FARC: Fuerzas Armadas Revolucionarias de Colombia.

FN: $\quad$ Frente Nacional.

UCR: Universidad Campesina de la Resistencia.

UP: $\quad$ Unión Patriótica. 